\title{
eLyra
}

\section{A reescrita como elemento intertextual na poesia brasileira contemporânea}

\author{
Diamila Medeiros dos Santos \\ Universidade Federal do Paraná (Brasil)
}

Resumo: A partir de dois poemas - de Ana Martins Marques e Angélica Freitas - e de dois livros - de Guilherme Gontijo Flores e Adriano Scandolara -, o presente artigo se dedica a analisar a reescrita como um processo intertextual comum não só entre essas obras, mas presente também na poesia brasileira contemporânea como um todo. Interessa-nos verificar o que esses mecanismos guardam de semelhança e diferença e as formas através das quais a reescrita empreendida é capaz de ironizar, deslocar e celebrar os poemas e textos com os quais dialoga, sempre de forma atual e produtiva.

Palavras-chave: Poesia brasileira, intertextualidade, reescrita

Abstract: From two poems - by Ana Martins Marques and Angélica Freitas - and two books - by Guilherme Gontijo Flores and Adriano Scandolara -, the present paper aims at an analysis of rewriting as a common intertextual process not only among these works, but also present in contemporary Brazilian poetry as a whole. We are interested in verifying what such mechanisms keep in common and where they differ and the ways through which the use of rewriting makes it possible to ironize, dislocate and celebrate the poems and texts they keep a dialogue with, always productively and updating it.

Keywords: Brazilian poetry, intertextuality, rewriting 


\author{
Escrever alguma coisa e dar-Ihe \\ o meu nome \\ como num contrato de aluguel \\ são minhas estas palavras de outros \\ por direito são minhas até não serem mais \\ são de outros são minhas \\ são os termos \\ do contrato
}

Ana Martins Marques

A intertextualidade - entendida de forma ampla e em suas múltiplas especificidades - vem sendo apontada, por vários críticos, como um traço comum de parte significativa da produção contemporânea de poesia brasileira e estrangeira. Isso se dá através da reiterada presença de nomes de artistas e de obras, trechos de canções, poemas ou de prosa, referências a séries de televisão e outros inúmeros elementos que compõem o mundo pop, como matéria formadora de poemas e de livros como um todo, sobretudo, a partir do fim dos anos 90 e das primeiras décadas do século XXI.

Wilberth Salgueiro descreve esse fenômeno em pelo menos dois textos: "A poesia brasileira lida numa antologia: exercícios de solidão" (2013) que analisa a Antologia Comentada da Poesia Brasileira do Século 21 (2006), de Manuel da Costa Pinto, e em “A tradição visível" (2017), no qual são comentadas mais três antologias, além desta de Pinto: Roteiro da Poesia Brasileira - anos 2000, de Marco Lucchesi (2009); Prévia Poesia, de André Dick (2010); e Poesia.br, de Sergio Cohn (2013), constituindo um corpus de 141 poetas e 528 poemas, no total. Luciana di Leone também o faz, através de uma comparação entre a poesia brasileira e a argentina, no livro Poesia e Escolhas Afetivas (2014), trazendo para o debate o que ela chama de poéticas do afeto, estabelecidas por meio de endereçamentos (de poemas), citações e nomes próprios. Segundo a autora, esses processos instauram na poesia uma nova ética que busca tanto formar novas coletividades quanto estabelecer uma crítica aos nossos atuais modelos de comunidade.

Marjorie Perloff, em seu incontornável O Gênio Não Original. Poesia por outros meios no novo século (2013), faz um percurso por todo o século XX, desde as Vanguardas, a poesia 
de T. S. Eliot e Ezra Pound, até o século XXI e as teorias de Kenneth Goldsmith (2011) acerca da escrita não-criativa, passando por reflexões sobre o Concretismo brasileiro e o Oulipo francês, para construir sua perspectiva, segundo a qual, a noção de originalidade - valor romântico por excelência - tem perdido a centralidade nas produções contemporâneas. Segundo Perloff, a inventio vem sendo substituída por diversos processos intertextuais que trazem ao centro dessa produção o diálogo com a tradição literária e artística:

No clima do novo século, porém, parecemos estar testemunhando uma reviravolta poética do modelo de resistência da década de 1980 para o diálogo - um diálogo com textos anteriores ou outras mídias, com a técnica do "escrever-através" ou écfrases que permitam ao poeta participar de um discurso maior e mais público. A inventio está cedendo espaço para a apropriação, a restrição elaborada, a composição visual e sonora e a dependência da intertextualidade. (Perloff 2015: 40-41)

Ainda outros críticos, como Antônio Donizeti Pires, "Lugares-comuns da lírica, ontem e hoje" (2007) e Paulo César Andrade da Silva, "Silêncio e diálogo na poesia brasileira" (2011), apontam para essa forte presença da intertextualidade no que se produz de poesia hoje, não só no Brasil. Pires reflete sobre o quanto essa prática "recorrente desde as origens da literatura principalmente de forma alusiva, apropriativa e genérica" (Pires 2007: s.p.) passa por "sensível incremento desde o século XIX" (idem: s.p.), modificando-se e ganhando várias nuances, na modernidade e na contemporaneidade. Ainda segundo o autor:

Moderna e contemporaneamente, a prática radical da intertextualidade crítica pode ser compreendida como a exploração (ainda que fragmentada e fragmentária, calcada e decalcada do palimpsesto da cultura) das "[...] ruínas do passado [...]" (Junqueira 1987: 95) com as quais amparar as “[...] ruínas do presente [...]" (95). (Pires 2007: s.p.)

Ou seja, embora o fenômeno da intertextualidade seja reconhecível em todos os momentos da história da literatura ocidental, é possível notar que na passagem para a modernidade e, posteriormente, para a pós-modernidade, chegando ao mundo contemporâneo, os procedimentos intertextuais ganharam singularidades que se desdobraram, na maior parte dos casos, em novas formas de se nomear esses mecanismos. Se, em meio às Vanguardas do início do século $X X$, as técnicas cubistas de colagem e bricolagem serviram de noção para se pensar também nos textos literários, como por 
exemplo naqueles produzidos pelo dadaísmo, hoje, vemos a emergência de termos que dialogam diretamente com modalidades de arte que prosperaram, sobretudo, a partir dos anos sessenta, como a ideia de pós-produção, relacionada ao cinema e à televisão, ou o sampler, prática habitual no mundo da música pop. Por outro lado, diante das demandas ambientais, cada vez mais urgentes, é possível pensar na intertextualidade como um intenso processo de reciclagem, dramatizando, no universo das artes, uma das possibilidades que teríamos enquanto civilização: reciclar, porque já não é mais possível e desejável criar a partir do nada. Além desses, é possível pensar em citação, reescrita, apropriação, pastiche, paródia, alusão, plágio, referência, e vários outros.

A partir disso, interessa-nos, aqui, pensar na questão da reescrita enquanto elemento relevante entre os procedimentos de intertextualidade da poesia brasileira contemporânea, já que a reconhecemos como uma característica profícua na concepção não só de poemas isolados, mas de livros inteiros que apresentam como projeto a reescritura de outros textos pertencentes à nossa tradição, sobretudo ocidental. A definição dessa noção, em muitos momentos, se contamina com as noções de outros procedimentos intertextuais igualmente presentes, o que remete às complexidades inerentes às definições de texto, intertexto, escrita e reescrita. Entretanto, essa contaminação teórica e crítica se constitui como mais uma possibilidade de demonstrar o quanto esses mecanismos subjazem nossas próprias perspectivas em relação à literatura.

As definições de texto, no decorrer do século $X X$, foram atravessadas por inúmeras teorias - como a filosofia da linguagem, a psicanálise, a análise do discurso - que encontraram diversas formas de apontar para o fato de que todo texto (entendendo-se texto de forma também ampla, como preconizado por Roland Barthes) é construído com base em textos anteriormente já formulados. Os discursos, ideias, modelos de construção discursiva, se interpenetram sistematicamente tornando impossível a delimitação entre o que é uma atribuição do outro e o que é um predicado único e exclusivo do eu que enuncia algo - se é que isso existe. Nesse sentido, Roland Barthes, em "Texto (Teoria do)", publicado em 1974, nos afirma que "todo texto é um intertexto; outros textos estarão presentes nele, em níveis variáveis, com formas mais ou menos reconhecíveis; os textos da cultura anterior e os da cultura ambiente; todo texto é um tecido novo de citações passadas" (Barthes 2004: 
275). Assim, por extensão, todo texto literário também se constitui de outros já anteriormente escritos, instaurando um exercício constante de reescrita como aspecto formador da própria noção de escrita literária. Antoine Compagnon, em La seconde main ou le travail de la citation (1979), importante estudo acerca da citação, também tensiona algumas das sobreposições entre essas noções:

Écrire, car c'est toujours récrire, ne difere pas de citer. La citation, grâce à la confusion métonymique à laquelle elle preside, est lecture et écriture; elle conjoint l'acte de lecture et celui d'écriture. Lire ou écrire, $c^{\prime}$ est faire acte de citation. La citation represente la pratique première du texte, au fondement de la lecture et de l'écriture; citer, c'est répéter le geste archaïque du découper-coller, l'expérienceoriginelle du papier, avant que celui-ci ne soit la surface d'inscription de la lettre, le support $d$ texte manuscrit ou imprimé, un mode de la signification et de la communication linguistique. (Compagnon 1979: 41)

[Escrever, porque é sempre reescrever, não difere de citar. A citação, graças à confusão metonímica que ela preside, é leitura e escrita, ela combina o ato de leitura e o de escrita. Ler ou escrever é fazer um ato de citação. A citação representa a prática primeira do texto, o fundamento da leitura e da escrita; citar é repetir o gesto arcaico de recortar-colar, a experiência original do papel, antes que ele seja a superfície de inscrição da letra, o suporte do texto manuscrito ou impresso, um modo da significação e da comunicação linguística (Tradução nossa)].

Segundo Compagnon, escrever, sendo sempre reescrever, acaba por ser um ato constante de citação, entretanto, isso encerra a especificidade da reescrita, tal como gostaríamos de explorar nesse trabalho, o que nos leva à necessidade de estabelecer alguns paradigmas. Assim, embora acreditemos que haja toda uma teia de textos e citações que atuam na construção de todos os textos, como entendido por ambos os autores franceses, para o presente estudo, utilizaremos apenas aqueles textos nos quais essas citações aparecem na superfície do texto, como marca direta do processo de reescrita empreendido. (Se não fosse feito dessa forma, acabaríamos por entrar em um trabalho infinito, já que poderíamos ler na poesia brasileira contemporânea, nosso objeto de estudo, todo e qualquer texto já anteriormente escrito.) Essas marcas diretas são variáveis: aparecem nas epígrafes, nas introduções, prefácios, posfácios e colofões dos livros, mas também em entrevistas e comentários dos poetas, acerca de seus processos de escrita. 
Na poesia de uma autora proeminente como Ana Martins Marques, por exemplo, é possível notar, em diversos momentos, o diálogo com outros poetas, brasileiros e estrangeiros, apresentado, sobretudo, a partir de suas epígrafes. Em Da Arte das Armadilhas (2011), pelo menos dois poemas revelam processos de reescrita de dois poetas norteamericanos, Elizabeth Bishop e E. E. Cummings. Analisaremos o primeiro deles que integra a seção do livro denominada "Interiores", na qual Marques - em sua habitual poética do cotidiano - revela os traços sublimes dos detalhes da casa:

Banheiro (Banho de Xampu)

d'après Elizabeth Bishop

com alguma coisa de Adília Lopes

Sem lembrança
de liquens
ou memória
do mar
de pé
sozinha
no banheiro
do apartamento
sem pretexto
para o pranto
- no more tears
rosnam os rótulos
da Johnson \& Johnson -
lavo eu mesma
meus cabelos
curtos
que um dia
você lavou
numa bacia
enquanto
como ela mesma


a amassada lua

brilha. (Marques 2011: 19)

Gérard Genette, em Paratextos Editoriais (2009), afirma que a epígrafe pode ter diferentes funções: a "[...] de comentário, às vezes decisivo - de esclarecimento, portanto, e como tal de justificativa, não do texto, mas do título [grifo do autor]" (2009: 141); a de comentário do próprio texto; e outra - mais oblíqua, segundo Genette - que guarda relação não tanto com o conteúdo da epígrafe, mas com seu autor, isto é, "[...] a identidade de seu autor e o efeito de caução indireta que sua presença determina à margem de um texto" (idem: 143).

No poema de Marques, podemos notar que a epígrafe cumpre, manifestamente, as duas primeiras funções. Em relação ao título, temos, entre parêntesis, a especificação de que não se trata apenas de um poema sobre o banheiro, mas sobre o "banho de xampu", direcionando seu leitor para a referência específica desse poema de Bishop, e, mais, para a referência específica da tradução de Paulo Henriques Britto, célebre, justamente por traduzir o título do poema como "Banho de xampu", ao invés de "O xampu", já que, em inglês, ele é intitulado "The shampoo". Além disso, a epígrafe explica também o próprio texto, à medida que aponta para o diálogo com Bishop, ao utilizar a expressão francesa "d'après", ou seja, "depois de", "de acordo com", "seguindo o modelo de", enfim, uma série de compreensões possíveis para essa locução. Entretanto, a segunda parte da epígrafe ("com alguma coisa de Adília Lopes") aponta mais para uma explicação do texto, aspecto que pode ser melhor demonstrado a partir da leitura da tradução de Bishop feita por Britto:

\footnotetext{
O banho de xampu

Os liquens - silenciosas explosões

nas pedras - crescem e engordam,

concêntricas, cinzentas concussões.

Têm um encontro marcado

com os halos ao redor da lua, embora

até o momento nada tenha mudado.
} 


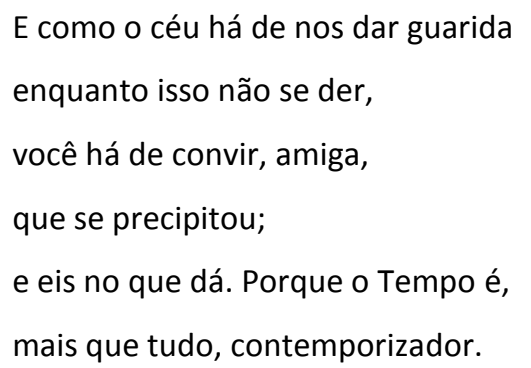

No teu cabelo negro brilham estrelas

cadentes, arredias.

Para onde irão elas

tão cedo, resolutas?

- Vem, deixa eu lavá-lo, aqui nesta bacia

amassada e brilhante como a lua. (Bishop 2011: 213)

O poema de Bishop apresenta versos mais longos, com palavras igualmente mais longas que o poema de Marques, no entanto, ele se faz reconhecível não só pelo título e pela epígrafe, mas também pelas escolhas de vocabulário (líquens, a imagem da lua, a bacia) e, sobretudo, pela presença desse eu-lírico que tem os seus cabelos lavados por alguém. Porém, Marques efetiva alguns deslocamentos em relação ao poema de Bishop: além dos versos curtos de duas, três ou quatro palavras, no máximo, em um processo de condensação das imagens apresentadas pelo primeiro poema, é possível observar algumas diferenciações de sentido entre ambos, já que, se em Bishop reconhecemos um poema de amor, em Marques, o eu-lírico vive o fim deste, o que é afirmado tanto nos versos que dizem "no more tears" - também referência à famosa propaganda da Johnson \& Johnson -, quanto na postura do eu poético que lava sozinho os próprios cabelos. Esse tom diferente entre os poemas guarda relação não só com a reescrita da própria Ana Martins Marques, mas também, e aqui retomamos a questão, pela parte da epígrafe que faz referência à Adília Lopes: a poeta portuguesa é conhecida por seus jogos intertextuais, permeados pela ironia e pela releitura das referências com as quais se relaciona recorrentemente em sua obra, em um intenso processo de apropriação e reescrita, da mesma forma como vemos acontecer no poema de Marques.

Outra poeta brasileira, Angélica Freitas, também utiliza em sua poética diversos procedimentos que podemos abrigar sob a grande rubrica da intertextualidade, de forma 
ampla, e sob a denominação da reescrita, de maneira específica. Seus jogos intertextuais guardam muitas semelhanças com os de Adília Lopes, já que são carregados de ironia, deboche e certa iconoclastia ao lidar com as referências. Um dos poemas mais conhecidos de seu livro de estreia, Rilke Shake (2007), foi escrito em um exercício de criação poética, durante uma oficina de Carlito Azevedo. Esse dado, entretanto, não nos é revelado pelo poema de Freitas, mas sim através de uma entrevista, o que Genette vai chamar de "epitexto público", isto é, "todo elemento paratextual que não se encontra anexado materialmente ao texto no mesmo volume, mas que circula de algum modo ao ar livre, num espaço físico e social virtualmente ilimitado" (Genette 2009: 303). Segundo Angélica Freitas, na entrevista em questão, a proposta era que os alunos escrevessem a partir do diálogo com o poema em prosa "O grande desastre aéreo de ontem", de Jorge de Lima, publicado em $A$ Túnica Inconsútil (1938), que transcrevemos abaixo:

O grande desastre aéreo de ontem

Para Portinari

Vejo sangue no ar, vejo o piloto que levava uma flor para a noiva, abraçado com a hélice. E o violinista em que a morte acentuou a palidez, despenhar-se com sua cabeleira negra e seu estradivárius. Há mãos e pernas de dançarinas arremessadas na explosão. Corpos irreconhecíveis identificados pelo Grande Reconhecedor. Vejo sangue no ar, vejo chuva de sangue caindo nas nuvens batizadas pelo sangue dos poetas mártires. Vejo a nadadora belíssima, no seu último salto de banhista, mais rápida porque vem sem vida. Vejo três meninas caindo rápidas, enfunadas, como se dançassem ainda. E vejo a louca abraçada ao ramalhete de rosas que ela pensou ser o paraquedas, e a prima-dona com a longa cauda de lantejoulas riscando o céu como um cometa. E o sino que ia para uma capela do oeste, vir dobrando finados pelos pobres mortos. Presumo que a moça adormecida na cabine ainda vem dormindo, tão tranquila e cega! Ó amigos, o paralítico vem com extrema rapidez, vem como uma estrela cadente, vem com as pernas do vento. Chove sangue sobre as nuvens de Deus. E há poetas míopes que pensam que é o arrebol. (Lima 2014: 129)

O poema de Jorge de Lima, dedicado a seu amigo e pintor Candido Portinari, recorre, não à toa, ao recurso da imagem de forma manifesta: podemos observar uma série de quadros de um suposto acidente aéreo que se acumulam na construção do texto. Há o 
piloto, o violinista, as dançarinas, enfim, uma série de personagens que, após a explosão do avião, são vistos por esse eu-lírico, muito semelhante a um narrador de prosa, que entremeia as descrições das imagens com a utilização da palavra "vejo".

No exercício proposto por Carlito Azevedo em sua oficina, a ideia era que os participantes escolhessem justamente um dos "personagens" apresentados pelo poema e escrevessem um outro em diálogo com este. O de Angélica Freitas toma emprestado não só o personagem do violinista, mas também um trecho do poema de Lima para nomear sua obra que segue transcrita abaixo:

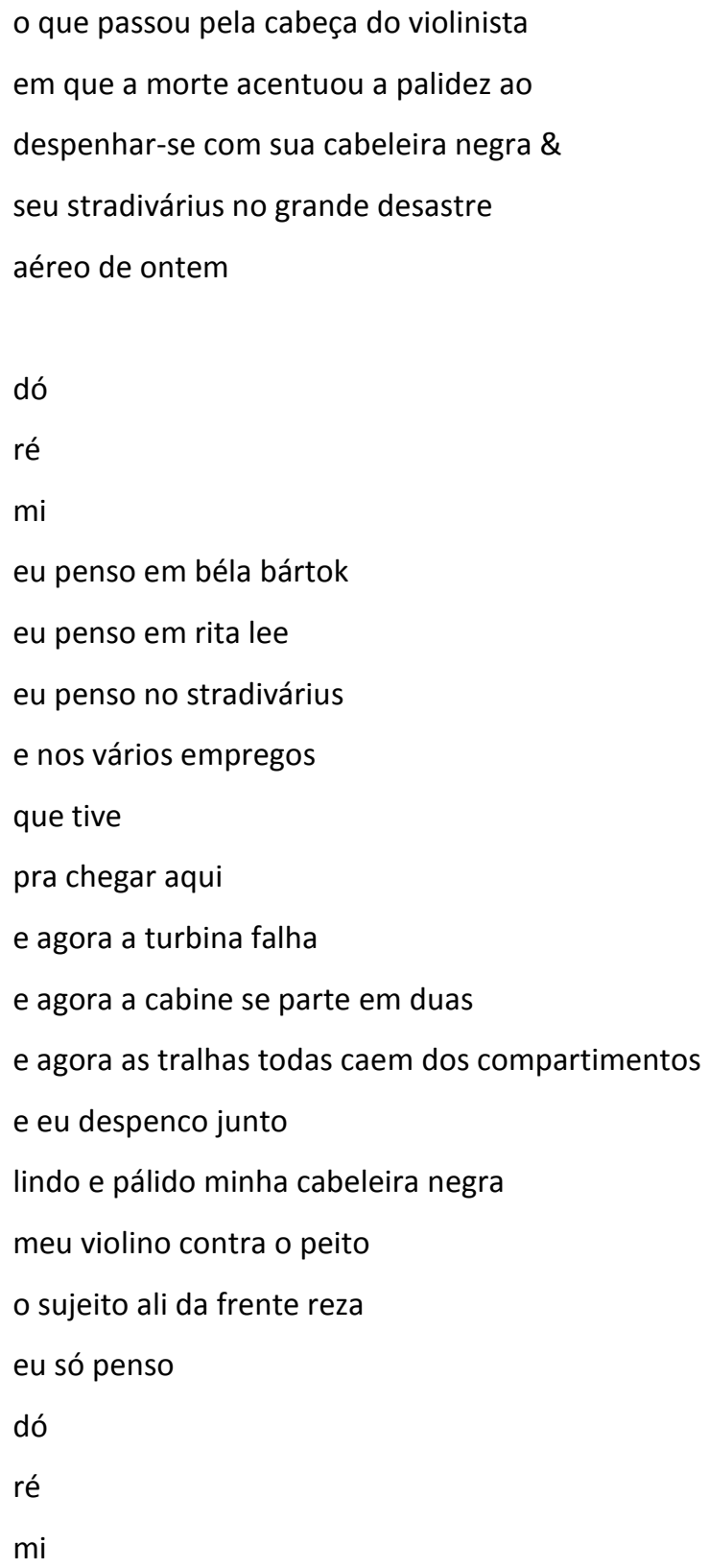




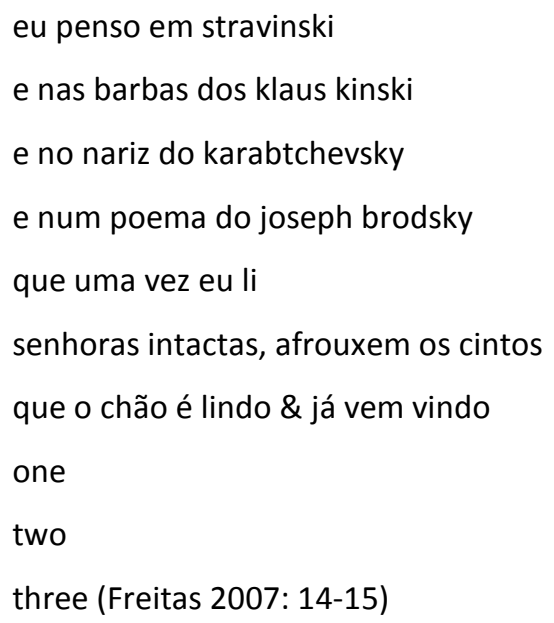

Freitas coloca o violinista como centro do poema e empreende, através dessa figura, não só a reescrita do acidente aéreo, mas também - como em Ana Martins Marques - uma compactação das imagens apresentadas e um deslocamento nas leituras possíveis do poema, através, sobretudo, da incorporação de seu costumaz tom de deboche e ironia. 0 poema incorpora ainda alguns elementos formais que o tornam extremamente interessante, como a escolha por fazê-lo em versos - e não mais em prosa - dramatizando, na forma, o próprio movimento de queda do violinista. As notas musicais "dó/ ré/ mi" tornam-se, no fecho do poema, uma contagem "one/ two/ three" que utilizada, normalmente, para dar início ao concerto, torna-se ali a enunciação do fim.

Outro aspecto relevante dessa reescrita tem relação com a incorporação de outras referências dos mundos erudito e pop, como Rita Lee (cantora brasileira), Béla Bartók (compositor húngaro), Igor Stravinski (compositor russo), Klaus Kinski (ator alemão), Isaac Karabtchevsky (maestro brasileiro), Joseph Brodsky (escritor russo). As sobreposições dessas instâncias culturais de matrizes diferentes, vinculam a poética de Angélica Freitas às tendências pós-modernas que se estabelecem justamente da desierarquização entre perspectivas como erudito e popular. Além disso, esses nomes, devido às suas sonoridades específicas e ao fato de serem, majoritariamente, nomes de músicos, trazem para o poema justamente uma musicalidade que o diferencia do poema de Jorge de Lima. Parece-nos que assim há também um deslocamento: se em "Grande desastre aéreo de ontem" havia uma dimensão visual fortemente evidenciada, em sua reescrita é outro sentido que acaba sendo convocado: a audição. 
Dessa forma, pudemos notar que esses dois poemas apresentados aparecem, nas obras de suas autoras, como produções nas quais podemos observar os mecanismos de reescrita que se constituem como exemplos da intertextualidade, embora haja outros exemplos de mecanismos diferentes, como a citação. Entretanto, como nos interessa observar questões de reescrita não só de poemas isolados, gostaríamos de observar que algumas obras de poesia contemporânea são construídas integralmente através da reescrita de outras poéticas. Dentre essas obras, podemos pensar em Tróiades (2015), de Guilherme Gontijo Flores e em Parsona (2017), de Adriano Scandolara.

Tróiades é o desdobramento de um poema-site construído do recorte, da tradução e do remanejamento de três poemas que versam sobre a derrota de Tróia: Troades, de Sêneca, Troiades e Hécuba, de Eurípedes, e de trechos do aforismo 9 de Walter Benjamin, do livro Sobre o Conceito de História. Aos poemas se juntam a imagens de diversos massacres (na Alemanha, na Tunísia, no Brasil, na Polônia, entre outros lugares) retiradas da Wikimedia Commons. No site, que toca recorrentemente "Genocide - Symphonic Holocaust" (2005), de Maurizio Bianchi, é possível ler cada um dos poemas ao clicar nessas imagens e no livroobjeto - composto por uma pequena caixa de papelão, com as fotografias separadas, como se fossem cartões postais - podemos ler os poemas nos versos dessas fotografias e também em um pequeno livro que acompanha as imagens. Todas essas informações são apresentadas tanto no poema-site, quanto no posfácio do livro que nos explica o seu processo de feitura.

O livro é, por excelência, um acontecimento na poesia contemporânea, uma vez que se instaura como um monumento que recorda o horror inerente à civilização humana, em sua constante atualização. Como nos diz Michel Deguy: "De que são feitas as obras de arte? De horror. A arte mergulha suas mãos no oceano de atrocidades, o inferno, e levanta alguns de seus pedaços, sangue e sânie, lágrimas, gritos" (Deguy 2010: 29). Porém, ao mesmo tempo que se constrói do horror, e Tróiades também nos lembra disso, a arte age como uma forma de resistência a ele, o que se nota em todo livro de Flores e ainda se afirma, uma vez mais, no colofão, onde vemos uma espécie de poema final que instaura uma série de marcas temporais do passado de horror e sua permanência:

nos 3200 anos do incêndio de Troia; 
2160 anos da aniquilação de Cartago;

805 anos do cerco de Béziers;

522 anos de extermínio indígena nas Américas;

369 anos da carnagem de Yangzhou;

117 anos da guerra de Canudos;

99 anos do genocídio armênio;

82 anos da grande fome da Ucrânia;

76 anos do estupro de Nanquim;

74 anos da fundação de Auschwitz-Birkenau;

69 anos de Hiroshima \& Nakasaki;

32 anos do massacre de Hama;

20 anos de genocídio em Ruanda;

11 anos de conflito em Darfur;

o tempo indeterminado da escravização do homem pelo homem. (Flores 2015: s.p.)

A proposta desse texto final empreende também, de alguma forma, um processo de reescrita da história que se sobrepõe ao próprio processo de escrita e publicação do livro. No site da Editora Patuá podemos ler o seguinte: "Quase todos os nossos livros (exceto por opção do autor) recebem um texto criado exclusivamente para constar no fim do livro. Este texto deve relacionar uma experiência particular do autor com o livro e com a proposta da editora, a de que livros são amuletos". Nesse processo de se olhar para a história da repetição do horror, o livro de Flores parece ser o próprio Angelus Novus, de Klee, tal como descrito por Benjamin, lançando seu olhar para o passado:

“Minha asa está pronta para o vôo

De bom grado voltaria atrás

Pois permanecesse eu também tempo vivo

Teria pouca sorte."

Gerhard Scholem, Salut de l'ange [Saudação do Anjo]. Existe um quadro de Klee intitulado "Angelus Novus". Nele está representado um anjo, que parece estar a ponto de afastar-se de algo em que crava o seu olhar. Seus olhos estão arregalados, sua boca está aberta e suas asas estão estiradas. 0 anjo da história tem de parecer assim. Ele tem seu rosto voltado para o passado. Onde uma cadeia de eventos aparece diante de nós, ele enxerga uma única catástrofe, que sem cessar amontoa escombros sobre escombros e os arremessa a seus pés. Ele bem que gostaria de demorar-se, de despertar os mortos e 
juntar os destroços. Mas do paraíso sopra uma tempestade que se emaranhou em suas asas e é tão forte que o anjo não pode mais fechá-las. Essa tempestade o impele irresistivelmente para o futuro, para o qual dá as costas, enquanto o amontoado de escombros diante dele cresce até o céu. O que nós chamamos de progresso é essa tempestade. (Benjamin apud Löwy 2005: 87)

O procedimento de escrita do livro, como já apontamos, compreende a tradução e o remanejamento dos textos, constituindo um processo de reescrita que, entretanto, instaura uma tensão entre a noção da reescrita e a de tradução, tal como no poema "Banheiro (Banho de xampu)" de Ana Martins Marques. No caso do poema de Marques, contudo, parece-nos que a reescrita se dá já a partir de uma tradução para o português, como apontamos, o que dissolve esse tensionamento. Já no caso do livro de Flores que é, importante lembrar, um tradutor reconhecido e multipremiado, as instâncias de reescrita e tradução acabam por se sobrepor. No entanto, isso não se configura como um problema, uma vez que podemos localizar teóricos da tradução que a entendem como um processo de reescrita por excelência, como o faz André Lefevere:

A Tradução é, certamente, uma reescritura de um texto original. Toda reescritura, qualquer que seja sua intenção, reflete uma certa ideologia e uma poética e, como tal, manipula a literatura para que ela funcione dentro de uma sociedade e de uma forma determinada. Reescritura é manipulação, realizada a serviço do poder, e em seu aspecto positivo pode ajudar no desenvolvimento de uma literatura e de uma sociedade. As reescritas podem introduzir novos conceitos, novos gêneros, novos recursos, e a história da tradução é também a história da inovação literária, do poder formador de uma cultura sobre outra. Mas a reescrita também pode reprimir a inovação, distorcer e controlar, e em uma época de crescente manipulação de todos os tipos, o estudo dos processos de manipulação da literatura, exemplificado pela tradução, pode nos ajudar a adquirir maior consciência a respeito do mundo em que vivemos. (Lefevere 2007: 11-12)

Essa perspectiva também dialoga com Compagnon quando este reflete sobre a obra de Jorge Luís Borges - reflexão que podemos estender a outros autores: "Car si l'écriture est toujours une récriture, de subtils mécanismes de régulation, variables selon les époques, œuvrent pour qu'elle ne soit pas simplement un recopiage, mais une traduction, une citation" (Compagnon 1979: 42). [Tradução nossa: Porque, se toda escrita é sempre uma 
reescrita, os mecanismos sutis de regulação, variáveis segundo a época, funcionam de modo que ela não seja simplesmente uma repetição da cópia, mas uma tradução, uma citação].

Assim, entendendo toda tradução como uma reescrita e levando-se em conta todo o aparato descritivo do processo de elaboração do livro, tal como fornecido por Flores no posfácio, é possível pensarmos que a obra em questão se dá através de um duplo processo de reescrita: enquanto tradução e enquanto reelaboração do que foi pensando pelos autores com os quais Flores dialoga. Interessante é que esse diálogo se forja não só com textos estritamente poéticos, mas também com um texto que podemos entender como teórico: o aforismo de Benjamin, transcrito acima. Este, por sua vez, como toda a escrita do autor alemão, apresenta elementos característicos de uma poética, de forma que podemos entendê-lo como um texto também literário, forjado através da écfrase da obra de Klee - o que faz com que o texto de Benjamin possa ser pensado como um processo de reescrita, compondo uma imagem fractal, já que as propriedades dessas obras - uma dentro da outra - se repetem continuamente.

Retornando ao livro de Flores, abaixo, segue o poema reescrito a partir de Benjamin:

Tombeau

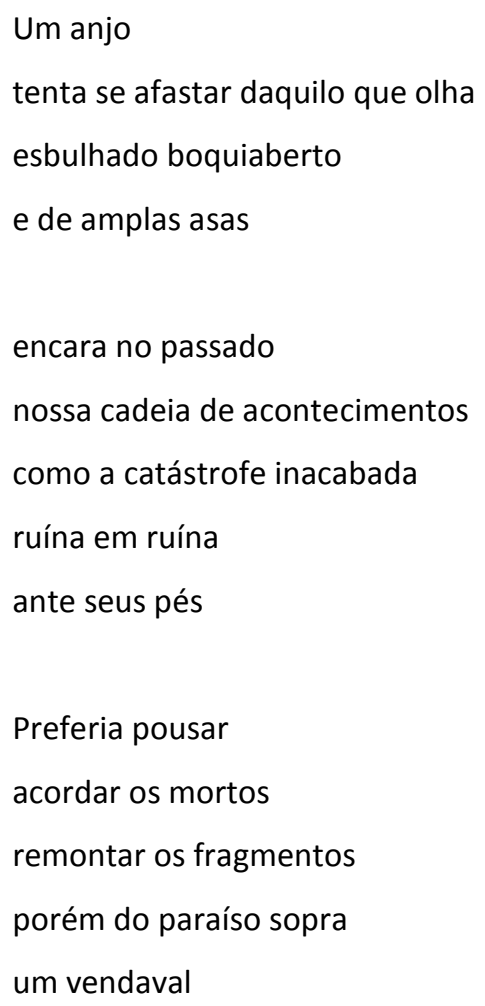




\author{
que enlaça suas asas \\ e ele não sabe \\ mais fechá-las \\ arrastado ao futuro \\ ele vai de costas \\ e a pilha de ruínas à sua frente \\ alcança o céu (Flores 2015: s.p.)
}

O poema de Flores é facilmente reconhecível como uma reescrita de Benjamin, para um leitor que tenha um contato básico com a obra do alemão, por várias imagens evocadas: o anjo que se afasta com as asas e os olhos muito abertos, os fragmentos e ruínas do passado que se amontoam diante dele e a impossibilidade de se virar e encarar o futuro, apesar da forte tempestade que o impele para a frente. A forma como o poema é escrito evoca muito dos procedimentos de Marques e Freitas ao estabelecer uma condensação das imagens dos textos com os quais cada um dialoga, mas essa abreviação é feita de uma maneira que permite - mais uma vez, a um leitor minimamente familiarizado - o reconhecimento dos poemas e textos de partida.

Estratégia interessante, mas um pouco diferente dessas, é a de Adriano Scandolara em Parsona (anagrama de "parnaso"), obra experimental, na qual o poeta reescreve os 35 sonetos do clássico parnasiano "Via Láctea" (1888), de Olavo Bilac. O livro é dividido em cinco partes, mais um poema introdutório e um posfácio, denominado "faça você também o seu próprio PARSONA" (Scandolara 2017: 129), que, embora esteja "fora" dos poemas, se constitui como parte fundamental destes, uma vez que empreende, através da simulação de um manual de instruções ou de uma receita, a organização do método rigoroso de reescrita realizado pelo livro.

O posfácio em questão também dá o tom da perspectiva do poeta ao escolher essa estratégia de trabalho: trata-se de um posicionamento irônico não só em relação à poética parnasiana, mas também em relação às Vanguardas (pensemos no dadaísmo e no surrealismo), ao Concretismo e também a algumas das tendências contemporâneas como as da uncreative writing, de Goldsmith. As instruções que vemos no posfácio remetem a cortes e subtrações que devem ser realizados nos poemas de partida, neste caso, os de Bilac. Já no decorrer do livro, em cada uma das partes, vemos o resultado desses procedimentos. Por 
exemplo, as três primeiras instruções determinam que se deve escolher 35 poemas de um poeta "morto há mais de 70 anos" (idem: 129) - debochando da questão dos direitos autorais - e que se deve mutilar esses poemas, "deixando espaços em branco no lugar das letras cortadas" (ibidem), o que resulta na parte primeira do livro: "tempo desvairado (em que mutilo sem dó os sonetos)" (idem: 19). Já nisso, podemos notar que Scandolara se apropria do viés contidamente erótico/amoroso de Via Láctea e o desdobra em um erotismo vulgar e zombeteiro. Como podemos notar na transição do poema XIX de Bilac que, em Scandolara, converte a via láctea em jorro de esperma (idem: 50), e também no caso do poema abaixo de Bilac:

XIX

Sai a passeio, mal o dia nasce,

Bela, nas simples roupas vaporosas;

E mostra às rosas do jardim as rosas

Frescas e puras que possui na face.

Passa. E todo o jardim, por que ela passe,

Atavia-se. Há falas misteriosas

Pelas moitas, saudando-a respeitosas...

É como se uma sílfide passasse!

E a luz cerca-a, beijando-a. O vento é um choro

Curvam-se as flores trêmulas... O bando

Das aves todas vem saudá-la em coro...

E ela vai, dando ao sol o rosto brando,

Às aves dando o olhar, ao vento o louro

Cabelo, e às flores os sorrisos dando... (Bilac 1888: s.p.)

Poema que, ao ser submetido aos procedimentos de Parsona, se transforma em: 


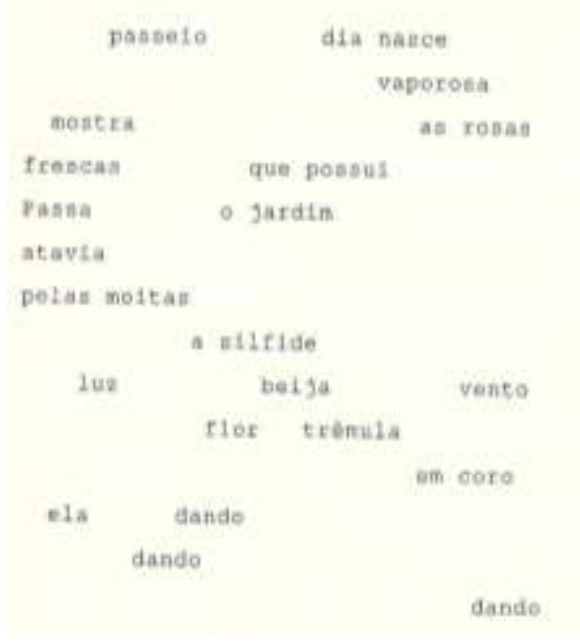

(Scandolara 2017: 40)

A natureza jocosa do poema aparece ainda em poemas que são resultados dos outros procedimentos sugeridos pelo "manual" do posfácio. Chiste que podemos observar na forma como as demais partes do livro são apresentadas: parte segunda: "ascende como se livre (em que o olho une estrelas e traça constelações)" (idem: 57); parte terceira: "tortura de exílio e atritos vazada no eterno (em que a força gravitacional elimina espaços vazios)" (idem: 89); parte quarta: "lixívia (em que damos uma olhada numa porção do que foi jogado fora" (idem: 107); parte quinta: "sagitário a* (enfim o cerne de todo esse trabalho sem sentido" (idem: 119). Desta última, emerge o que seria, enfim, o que se buscou durante todo o livro: um poema final, escrito da junção de todos os recortes efetuados pelo poeta:

\footnotetext{
falo com fogo em teu seio, neblina

e alta noite curva estes céus erecta

sombria lembrança as estrelas trêmulas

chaves frescas que possui o luar

tão cego enfim seus enganos agora,

doce esmola o primeiro olhar solto

do teu, exílio apesar de ofendido

na treva a névoa pálpebras medrosas
}

olhar neles eleva tinge a aurora

esses beijos essas feridas penso

e terna primavera um turbilhão 
o derradeiro violento céu serras

chorando desce, entre estrelas morre

olha-me sereno ( ) ouvir estrelas (idem: 123)

Interessante nesse poema derradeiro é que - apesar de todas as mutilações e sobreposições que redundam em versos de sintaxe corroída e sentido opaco - há algo que se mantém da dicção de Bilac, ao menos como traço, potencializando as frases finais apresentadas pelo livro, em caixa alta: “BILAC DISSE TUDO ISSO/ BILAC NÃO DISSE NADA DISSO" (idem: 125). Nisso, é possível entrever o que sugere Emmanuel Santiago, na orelha do livro, e a epígrafe, extraída de George Steiner, isto é, a imagem da ruína como um paradigma do trabalho feito por Scandolara, o que nos faz pensar em certa semelhança com o trabalho de Gontijo Flores, afora, obviamente, as singularidades de suas obras.

Parsona se estabelece como um duplo movimento, pois, ao mesmo tempo que se utiliza dessa ruína da tradição, garante a ela uma possibilidade de se reinventar e tornar-se viva novamente, como apontado por Santiago, mais uma vez na orelha do livro: "Percebe-se que tal dessacralização possui um caráter ambíguo, pois - ao mesmo tempo que desconstrói - atualiza, resgata e dá crédito". E isso se dá justamente pela incorporação de algo que podemos observar como tendência, sobretudo, das artes performáticas, da segunda metade do século XX: a demonstração, em primeiro plano, do que se entende como processo de construção da obra e não mais apenas o seu resultado final e acabado.

Dessa forma, mesmo levando em conta que os procedimentos empregados tenham singularidades e características específicas, é possível perceber que a reescrita desempenha a possibilidade de atualizar obras que fazem parte de nossa tradição. A perspectiva da atualização não se relaciona aqui com a compreensão de que essas obras reescritas sejam velhas e/ou ultrapassadas, o que se sugere é que, como entendido por Pierre Lévy: "A atualização é criação, invenção de uma forma a partir de uma configuração dinâmica de forças e de finalidades" (Lévy 1996: 16). Ou seja, atualizar é dar outra possibilidade de vida e de circulação a obras que são, elas mesmas, as bases de nossas compreensões acerca do literário, tensionando essas compreensões e instaurando "uma produção de qualidades novas, uma transformação das ideias" (idem: 17). O que se estabelece, dessa forma, é a 
reescrita de nossa própria noção de criação e de inventividade, forjando outros lugares de ancoragem para o eu-criador contemporâneo, tal como apontado por Marjorie Perloff:

\footnotetext{
Uma vez que concedamos que as práticas atuais da arte têm o seu próprio momento e inventio particulares, podemos desassociar a palavra original de sua parceira, a palavra gênio. Se a nova poesia "conceitual" não alega possuir qualquer originalidade - ou pelo menos não a originalidade no sentido comum - isso não quer dizer que não haja gênio em jogo. São necessárias apenas formas distintas. (Perloff 2015: 54)
}

\section{Bibliografia}

Barthes, Roland (2004), "Texto (teoria do)", in Inéditos. Vol. 1 - Teoria, tradução de Ivone Castilho Benedetti, São Paulo, Martins Fontes, 261-289.

Bilac, Olavo (1888), Via Láctea, http://www.dominiopublico.gov.br/download/ texto/ua000252.pdf (último acesso em 28/09/2018).

Bishop, Elizabeth (2011), Poemas escolhidos, seleção, tradução e textos introdutórios de Paulo Henriques Britto, São Paulo, Companhia das Letras.

Coelho, Alexandra Lucas (2013), “Diz-me com quem te deitas, Angélica Freitas Público, 09 de junho, http://blogues.publico.pt/atlantico-sul/2013/06/09/diz-me-com-quem-te-deitasangelica-freitas/ (último acesso em 28/09/2018).

Compagon, Antoine (1979), La seconde main ou le travail de la citation, Paris, França, Éditions du Seuil.

Cohn, Sergio (org.) (2013), Poesia.br, Rio de Janeiro, Azougue.

Deguy, Michel (2010), Reabertura após Obras, tradução de Marcos Siscar e Paula Glenadel, Campinas-SP, Editora da Unicamp. 
Dick, André (org.) (2010), Prévia Poesia, São Paulo, Risco.

Flores, Guilherme Gontijo (2015), Tróiades, São Paulo, Patuá.

Freitas, Angélica (2007), Rilke Shake, São Paulo, Cosac \& Naify; Rio de Janeiro, 7Letras.

Genette, Gérard (2009), Paratextos Editoriais, tradução de Álvaro Faleiros, Cotia-SP, Ateliê Editorial.

Goldsmith, Kenneth (2011), Uncreative Writing, Nova York, Columbia University Press.

Lefevere, André (2007), Tradução, Reescrita e Manipulação da Fama Literária, tradução de Claudia Matos Seligmann, Bauru, SP, Edusco.

Leone, Luciana di (2014), Poesia e Escolhas Afetivas. Edição e escrita na poesia contemporânea, Rio de Janeiro, Rocco.

Lévy, Pierre (1996), O que é o Virtual?, tradução de Paulo Neves, São Paulo, Editora 34.

Lima, Jorge de (2014), "A túnica inconsútil", in Antologia Poética: Jorge de Lima, seleção e posfácio de Fabio de Souza Andrade, São Paulo, Cosac Naify, 129.

Löwy, Michael (2005), Walter Benjamin: Aviso de Incêndio - Uma Leitura das teses "Sobre o conceito de história", São Paulo, Boitempo.

Lucchesi, Marco (org.) (2009), Roteiro da Poesia Brasileira. Anos 2000, São Paulo, Global.

Marques, Ana Martins (2011), Da Arte das Armadilhas, São Paulo, Companhia das Letras.

Perloff, Marjorie (2015), O Gênio não Original. Poesia por outros meios no novo século, tradução de Adriano Scandolara, Belo Horizonte, Editora UFMG.

Pinto, Manuel da Costa (2006), Antologia Comentada da Poesia Brasileira do Século 21, São Paulo, Publifolha.

Pires, Antônio Donizeti (2007), "Lugares-comuns da lírica, ontem e hoje", Linguagem Estudos e Pesquisas, UFG, vols. 10 e 11, s.p.

Salgueiro, Wilberth (2013), "Notícia da atual poesia brasileira - dos anos 1980 em diante", O Eixo e a Roda, vol. 22, n $\cong 2,15-38$. 
-- (2013), "A poesia brasileira lida numa antologia: exercícios de solidão", Texto Poético, vol. 15, 20 semestre, 79-108.

-- (2017), "A tradição visível”, in Poesia Contemporânea e Tradição. Brasil \& Portugal, São Paulo, Alameda, 146-159.

Silva, Paulo César Andrade (2011), "Silêncio e diálogo na poesia brasileira", Cadernos de Semiótica Aplicada, vol. 9, n², Araraquara, 1-17.

Scandolara, Adriano (2017), Parsona, Curitiba, Kotter Editorial.

Diamila Medeiros dos Santos é doutoranda do Programa de Pós-Graduação em Letras pela Universidade Federal do Paraná (2016), ênfase em Estudos Literários, com pesquisa sobre poesia brasileira contemporânea. Tem graduação em Letras-Português pela Universidade Federal do Paraná (2013) e mestrado em Letras pela mesma instituição com dissertação sobre a obra do poeta contemporâneo Marcelo Ariel. Atualmente, é também da licenciatura em francês (UFPR). Tem experiência na área de Letras-Estudos Literários, atuando principalmente nos seguintes temas: teoria e crítica literária; poesia brasileira; poesia francesa; incentivo à leitura. Bolsista CAPES. 